\title{
Measures and Markers in Amyotrophic Lateral Sclerosis
}

\author{
Merit Cudkowicz,* Muhammad Qureshi,* and Jeremy Shefner ${ }^{\dagger}$ \\ *Neurology Clinical Trial Unit, Massachusetts General Hospital, Charlestown, Massachusetts 02129; and ${ }^{\dagger}$ Department of \\ Neurology, State University of New York Upstate Medical University, Syracuse, New York
}

\begin{abstract}
Summary: Amyotrophic Lateral Sclerosis (ALS) is a neurodegenerative disorder characterized by loss of spinal and cortical motor neurons, leading to progressive weakness and ultimately, death. Clinically, there appears to be an anatomic focus at disease onset, from which the disease then spreads. Because the focus of initial symptoms and the subsequent direction of spread can vary from patient to patient, disease monitoring is difficult, especially in a clinical trial, in which outcome measures must be identical and able to capture progression of all types. Thus, the search for markers of disease progression is
\end{abstract}

especially important in ALS. Many approaches have been taken, from voluntary strength assessment and functional rating scales to physiological and pathological sampling of affected portions of nervous system. No proposed marker has been demonstrated to meet the desired criteria of biological meaning, sensitivity to disease progression, clear relationship to overall prognosis and survival, and ease of measurement. However, progress is being made in all of these regards. Key Words: ALS, outcome measures, ALSFRS, motor unit number estimate.

\section{INTRODUCTION}

Because ALS is ultimately a fatal disease, survival is an obvious choice as a marker of disease progression, as well as success or failure of experimental trials. However, as a clinical trial outcome measure, survival has a number of limitations. First, because average survival of patients newly diagnosed with ALS is $>3$ years, use of survival as an endpoint obligates the use of long trial duration. Secondly, although survival seems unequivocal as an endpoint, its identification may be problematic, and it may be affected by other factors besides disease-modifying therapies. For example, the use of non-invasive ventilatory techniques may prolong life independent of disease progression; without question, tracheostomy and permanent assisted ventilation is a life-prolonging intervention. Invasive treatments to augment nutrition via gastrostomy tubes may also prolong survival. Thus, although survival is an objective, easily measurable outcome, it may reflect other factors than disease progression. The presence of surrogate markers of disease progression would allow for improved clinical trial design, and would increase our knowledge of the manner in

Address correspondence and reprint requests to Merit Cudkowicz, M.D., Massachusetts General Hospital, 13th Street, Building 149, Charlestown Navy Yard, Neurology Clinical Trial Unit, Charlestown, MA 02129. E-mail: mcudkowicz@ partners.org. which ALS evolves. This chapter will review diagnostic markers, markers that have been previously employed as outcome measures in clinical trials, and new approaches that may prove useful both as measurement tools and as probes into the biology of ALS.

\section{CLINICAL FEATURES AND DIAGNOSIS}

Amyotrophic lateral sclerosis is a rare degenerative disorder of large motor neurons of the cerebral cortex, brain stem, and spinal cord that results in progressive wasting and paralysis of voluntary muscles. ${ }^{1}$ Fifty percent of ALS cases die within 3 years of onset of symptoms and $90 \%$ die within 5 years. $^{2}$ The cause in most cases is unknown. No treatment prevents, halts or reverses the disease, although marginal delay in mortality has been recently noted with the drug Riluzole. ${ }^{3,4}$ The majority of cases are sporadic ALS (SALS); $10 \%$ are familial ALS (FALS). Mutations in the gene encoding cytosolic copper-zinc superoxide dismutase (SOD1) have been robustly identified as causing typical FALS. ${ }^{5}$ The median age of onset is 55 years and the median survival is $\sim 3$ years. Essential features of ALS are progressive signs and symptoms of lower motor neuron dysfunction, including focal and multifocal weakness, atrophy, cramps, and fasciculations associated with corticospinal tract signs (spasticity, enhanced and pathological reflexes) in the absence of sensory findings. ALS can 
present with only lower or upper motor neuron involvement, and the initial manifestations may be in either the limb or bulbar muscles. With disease progression, both upper and lower motor neurons are involved, as are both bulbar and limb muscles. These features define classic ALS.

At present, ALS is diagnosed when both upper and lower motor signs are present. ${ }^{6-8}$ In some cases, diagnostic electromyography (EMG) and muscle biopsy provide objective evidence of lower motor neuron involvement. Because upper motor neuron signs may be masked when LMN involvement is severe, upper motor neuron involvement can be missed. ${ }^{7,9}$ Sensitive and objective methods are needed to detect upper motor neuron involvement. Recent novel technologies such as magnetic resonance spectroscopy (MRS) promise to improve detection of upper motor neuron involvement. ${ }^{10-15}$

\section{ALS GENETICS}

In 1993 it was reported that mutations in the gene encoding SOD1 account for about $25 \%$ of cases of FALS or $2-3 \%$ of all cases. ${ }^{5}$ More than 100 different mutations in the SOD1 gene have now been associated with FALS. Forced expression of high levels of a mutant SOD1 transgene causes progressive motor neuron disease in mice and rats. ${ }^{16}$ It now seems likely that the fundamental pathology mediated by mutant SOD1 involves both aberrant copper catalysis as well as protein misfolding. ${ }^{17}$ In turn, these adverse properties invoke multiple downstream pathophysiological events including heightened excitoxicity mediated by glutamate, activation of cascades of programmed cell death, ${ }^{18,19}$ perturbation of calcium metabolism, depression of mitochondrial function and ATP production, activation of the stress response in endoplasmic reticulum, and slowing of axonal transport. ${ }^{20}$ Last year, a second ALS gene was discovered. ${ }^{21,22}$ The ALS2 gene codes for a novel protein with homology to guanine-nucleotide exchange factors for GTPases. Loss-of-function of ALS2 leads to denervation beginning in the first decade, with predominant corticobulbar and corticospinal signs and very slow progression. More recently, a study reported that a slowly progressive, bulbar-predominant form of lower motor neuropathy arises from mutations in a dynactin gene, ${ }^{23}$ confirming the principle that motor protein defects can progressively impair motor neuron function, as reported for motor neuropathies from mutations in the kinesin gene. ${ }^{24}$ New loci in dominant ALS have been reported on the X-chromosome ${ }^{25}$ and chromosomes $18 \mathrm{q} 21,9$, and $16^{26,27}$

\section{MARKERS RELATED TO FUNCTION}

\section{Muscle strength}

Muscle strength is a clinically relevant measure of disease progression in ALS. There are a variety of methods of varying sophistication available to measure mus- cle strength. The measures most often used in natural history studies and clinical trials are maximum voluntary isometric contraction (MVIC) and manual muscle testing (MMT).

Maximum voluntary isometric contraction. The MVIC has proven useful as an outcome measure in natural history studies and clinical trials in ALS and is a valid and reliable measure of disease progression. ${ }^{29-35}$ MVIC can be measured using a hand-held dynamometer or a fixed device with strain gauges. The strength of individual muscle groups is determined quantitatively and then the scores are normalized and combined into composite scores called megascores. This allows for the averaging of strength of small and large muscle groups. ${ }^{29}$

Intrarater and inter-rater reliability have been assessed in a number of clinical trials in ALS. With rigorous training of clinical evaluators, intra- and inter-rater reliability are less than $15 \% .{ }^{36,37}$ Seven trials testing four different therapeutic agents have used MVIC as the primary outcome measure. The methods used to determine the rate of decline in MVIC differ slightly among the clinical trials, with some trials using a mean slope and others a mixed model. However, the rate of change in MVIC has been consistent in the placebo groups from these studies. ${ }^{32-34,38}$ This suggests that, similar to the survival, muscle strength measures of disease progression in ALS have not changed over time. Data from the placebo treatment arms of two recent clinical trials with topiramate and creatine demonstrate that the rate of decline in MVIC is essentially linear with only a small quadratic component. $^{34}$

The relationship between muscle strength measured by MVIC and survival is not entirely clear. Two studies have demonstrated that the rate of decline in muscle strength measured by MVIC was strongly related to survival $^{34,39}$ and another found that neither the baseline limb muscle strength nor the rate of change in muscle strength preceding the trial was a significant predictor of survival. ${ }^{40}$ We examined the relationship of MVIC to survival in 97 subjects assigned to the placebo arm of the topiramate ALS study. The baseline MVIC arm score predicted survival, therefore subjects with lower baseline MVIC scores survived a shorter amount of time. The rate of decline of MVIC in the first 3 months was also predictive of survival.

The MVIC is a good quantitative measure of the rate of decline of muscle strength, an outcome measure that is highly relevant to the disease. The advantages of MVIC include good intrarater and inter-rater reliability, sensitivity to small, clinically relevant changes and generation of numerically continuous data which are suitable for parametric statistical analysis.

Problems that limit the use of MVIC are: it takes approximately $45 \mathrm{~min}$ to perform testing, requires expensive equipment, is not applicable for home visits, and 
data can not be obtained from very weak muscles. In the trials that used MVIC as an outcome measure, the study dropout rate has been between 20 and $40 \%$. This large amount of missing data can negatively impact the interpretability of the study results. A faster, portable method to measure strength is desired.

A promising technique uses hand-held dynamometry (HHD) to test isometric strength of multiple muscles, again with standard patient positioning and rigorous training. This technique has been used previously in ALS clinical trials, as well as in trials in patients with inflammatory neuropathy and muscular dystrophy. ${ }^{41-43}$ It has been directly validated against MVIC in ALS patients, and shown to change at a similar rate with variability that is only slightly greater than MVIC. ${ }^{44}$ For both upper and lower extremity muscles, correlations between MVIC and HHD measurements ranged between 0.84 and 0.92 , with test-retest variability that was extremely similar as well. The only time at which correlation between HHD and MVIC broke down was at extremely high strength levels, an area not likely to be a problem in an ALS clinical trial. HHD equipment is inexpensive and it takes less than $5 \mathrm{~min}$ to complete a test of both upper and lower extremities.

Manual muscle testing. Manual muscle testing (MMT) using the Medical Research Council (United Kingdom) grading scale has been used in a number of ALS clinical trials. It involves measurement of muscle strength by a trained evaluator using standardized patient positioning. It was recently demonstrated that if enough muscles are tested, a decline in average grade can be determined early in the disease, and the variability of measurement approximates that of MVIC. ${ }^{45}$ The advantages to manual muscle testing are speed, expense, and the lack of needed equipment. ${ }^{46,47}$ Disadvantages to MMT are low sensitivity to change in muscle strength, the fact that data are ordinal, qualitative, and potentially subjective, in addition to which a large number of muscles must be evaluated to reduce variability and improve sensitivity. $^{48}$

\section{Pulmonary}

Respiratory failure is the primary cause of death in ALS and measurements of respiratory muscle function are commonly used as secondary outcome measures in ALS clinical trials. Vital capacity and maximal inspiratory and maximal expiratory mouth pressures are the methods most commonly used to evaluate respiratory muscle strength. These measures are widely available, non-invasive, and portable. However, these tests are associated with increased variability in patients with significant bulbar involvement and require maximal respiratory muscle activation. ${ }^{49}$ Bulbar or facial weakness can prevent the formation of a tight lip-seal around a mouthpiece. Vocal cord spasms and excessive saliva and gag- ging can also interfere with study performance. Other measures of respiratory muscle function that might be more useful in patients with bulbar involvement and as outcome measures include maximal sniff esophageal, transdiaphragmatic, and nasal pressures.

The forced vital capacity (FVC) measures volume of air forcefully expired in one breath. Usually, the FVC is reported as a percentage of a predicted vital capacity based on subject's height, gender and age. The FVC declines with time in patients with ALS and is a sensitive measure of disease progression. Both the baseline FVC and the rate of decline in FVC are predictive of survival. ${ }^{40,50,51}$

Maximal inspiratory pressure (MIP) measures the maximal negative pressure at the mouth after complete exhalation followed by a single sustained maximal inspiratory effort against an occluded airway. Maximal expiratory pressure (MEP) is the maximal positive pressure measured at the mouth after inhalation to total lung capacity followed by a maximal expiratory effort against an occluded airway. ${ }^{52}$ Both MIP and MEP are sensitive early indicators of respiratory muscle weakness. They are easy to determine and reproducible.

\section{Functional rating scales}

Clinical rating scales that assess the activities of daily living (ADL) are useful in both natural history studies of ALS and in clinical trials of experimental agents. Early examples are the Norris scale and the ALS severity scale. The two scales most commonly used in ALS clinical trials include the Appel ALS rating and the ALS Functional Rating Scale (ALSFRS).

Appel ALS rating scale. The total Appel score consists of five subscores: bulbar, respiratory, muscle strength, and lower extremity and upper extremity function. Each group is composed of individual tests. A group score of six is assigned if there is no dysfunction and group scores of 30-36 points are assigned for maximal dysfunction. The total Appel ALS score is 30 for healthy subjects and 164 for those with maximum impairment. ${ }^{53}$ The rate of change in the Appel ALS Rating Scale is a significant predictor of survival for subjects with ALS. ${ }^{54}$

ALS functional rating scale. The ALSFRS is a quickly administered ordinal rating scale used to determine patients' assessment of their capability and independence in 10 functional activities. All 10 activities are relevant in ALS. It assesses bulbar and respiratory functions, upper extremity functions (cutting food and dressing), lower extremity functions (walking and climbing), and dressing hygiene and ability to turn in bed. The instrument can be easily administered by a clinician, an allied health professional, or a trained evaluator. The patient's response is recorded to the closest approximation from a list of five choices. Each choice is scored 
from 0 to 4 . The total score can range from 40 (normal function) to 0 (unable to attempt the task).

Initial validity was established by documenting that in ALS patients, change in ALSFRS scores correlated with change in strength over time, as measured by MVIC, ${ }^{55}$ was closely associated with quality-of-life measures, and predicted survival. ${ }^{51,56-58}$ With appropriate training the ALSFRS can be administered with high inter-rater reliability and test-retest reliability. The test-retest reliability is $>0.88$ for all test items.

The ALSFRS can be administered by phone, again with good inter-rater and test-retest reliability, but the equivalency of phone and in-person testing has not been determined. In addition, the ALSFRS can be administered to the patient directly when the patient is verbal, but as communication becomes more difficult, caregivers provide increasing assistance in providing responses. The equivalency of caregiver and patient responses has also not been established.

A revised version of the ALSFRS was created to add assessments of respiratory dysfunction, including dyspnea, orthopnea, and the need for ventilatory support. ${ }^{57}$ The revised ALSFRS (ALSFRS-R) was demonstrated to retain the properties of the original scale and show strong internal consistency and construct validity.

\section{MARKERS RELATED TO PATHOPHYSIOLOGY}

\section{Pathology}

Biopsy studies. Before the development of clinical neurophysiology more than 50 years ago, pathology served as the only quantitative measure of disease activity in ALS. Early autopsy studies demonstrated that ventral roots were atrophied as compared with dorsal roots $^{59}$; shortly thereafter, Charcot and Joffroy ${ }^{60}$ described the loss of large ventral horn neurons, degeneration of the corticospinal tract, and dropout of large cortical neurons in frontal cortex. More current postmortem studies continue to yield important information relevant to the pathogenesis of ALS, ${ }^{61-66}$ but will not be further reviewed here, as they do not serve as tools for diagnosis or disease progression.

Muscle biopsy is the only pathological tool that continues to be employed in the management of patients with ALS. The demonstration of denervation atrophy of muscle fibers is usually associated with increased connective tissue; unlike other denervating diseases such as neuropathy, muscle fiber type grouping is less uniformly observed. ${ }^{67,68}$ Muscle biopsy is useful in patients for whom the involvement of lower motor neurons is in doubt either clinically or physiologically. It is not part of the routine evaluation at most centers, but remains a useful ancillary test in atypical patients.

\section{Noninvasive markers of upper and lower motor neuron dysfunction}

Motor unit number estimates. Although routine nerve conduction studies and needle EMG are essential for confirming lower motor neuron involvement in the initial diagnosis of motor neuron disease, they do not permit accurate measurement of motor neuron loss and compensatory reinnervation. ${ }^{69,70}$ Motor nerve conduction velocity remains normal until quite late in the disease, and compound motor action potential amplitude does not decline until $>50 \%$ of axons has been lost. Needle EMG is a sensitive indicator of axon loss, but has not been useful in assessing change over time. Motor unit number estimation (MUNE) quantifies the number of surviving motor units in the living human subject ${ }^{71-76}$ and has emerged as an important potential marker in $\mathrm{ALS}^{77-79}$ and other motor neuron disorders.

All techniques for counting motor units rely on the same basic premise. A maximum muscle response is generated to an electrical stimulus. Most often the response measured is electrical, but force measurements have also been used. Then, the response amplitude of a single motor unit is estimated. Once a single motor unit amplitude estimate is made, this value is divided into the maximum response to yield a number reflecting the number of units that made up the response.

The way this estimation is made varies from technique to technique. No technique has been universally accepted, but 4 have emerged as the most commonly used. The original incremental technique described by $\mathrm{McCo}-$ $\operatorname{mas}^{81-83}$ relied on stimulating at one location, using a stimulus that varied slightly from near-threshold levels. Initially, an all-or-none response was generated, representing the response of a single unit. With increases in stimulus intensities, quantal increments in the response could be recorded, which were taken to represent additional motor units being stimulated (FIG. 1). Approximately 10 successive increments were recorded. That response amplitude was then divided by the number of increments to yield an estimate of average motor unit size.

The multiple point stimulation technique ${ }^{75,84,85}$ also relies on low-amplitude stimuli to generate a single allor-none response. Instead of increasing stimulus intensity to study successive increments, however, the stimulus position is varied, and the first unit, stimulated at a variety of positions, is recorded. Usually 10-20 such responses can be obtained; this sample of individual motor units is then averaged to yield an estimate of motor unit size. Spike-triggered averaging ${ }^{71,74}$ employs a different approach. Single motor units are identified at low levels of voluntary muscle activation. The response to a single motor unit is recorded with either a concentric or single-fiber EMG needle, and the electrode is positioned so that only the single motor unit response is 
recorded. Concurrently, surface potentials are recorded; the single motor unit spike is used as a trigger to timelock the surface-recorded potentials so that an average surface response can be calculated, corresponding to the needle-recorded spike. Different motor units are recorded by altering the position of the intramuscular electrode to trigger on different signals. The surface-averaged potentials are themselves averaged to derive an

A.

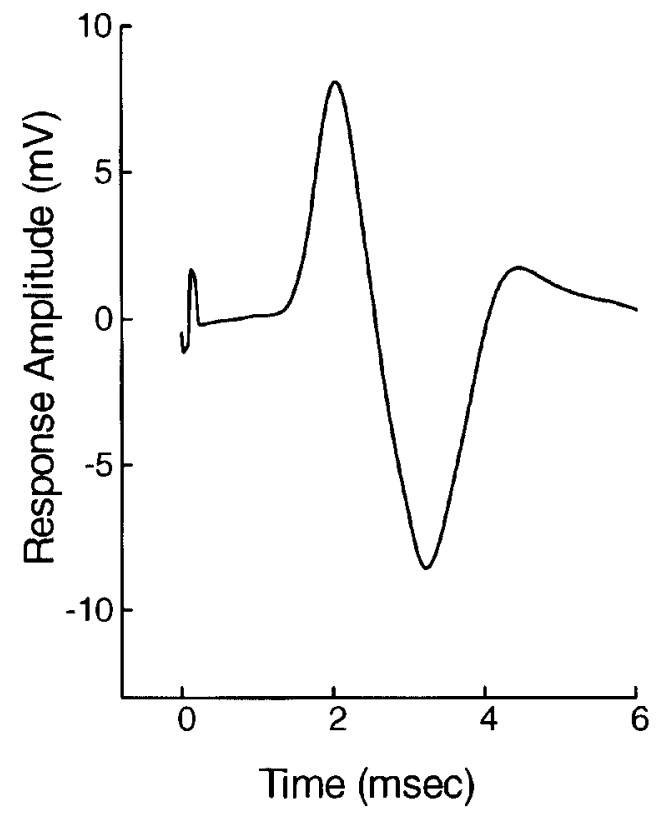

estimate of motor unit size. Finally, the statistical technique $80,86,87$ relies on the response variability to a repeated submaximal stimulus to estimate motor unit size. For any given submaximal stimulus intensities, some motor units will always fire because their response thresholds have been exceeded, some units will never fire because they are clearly subthreshold, and some will fire variably as the stimulus is near their threshold level.

B.

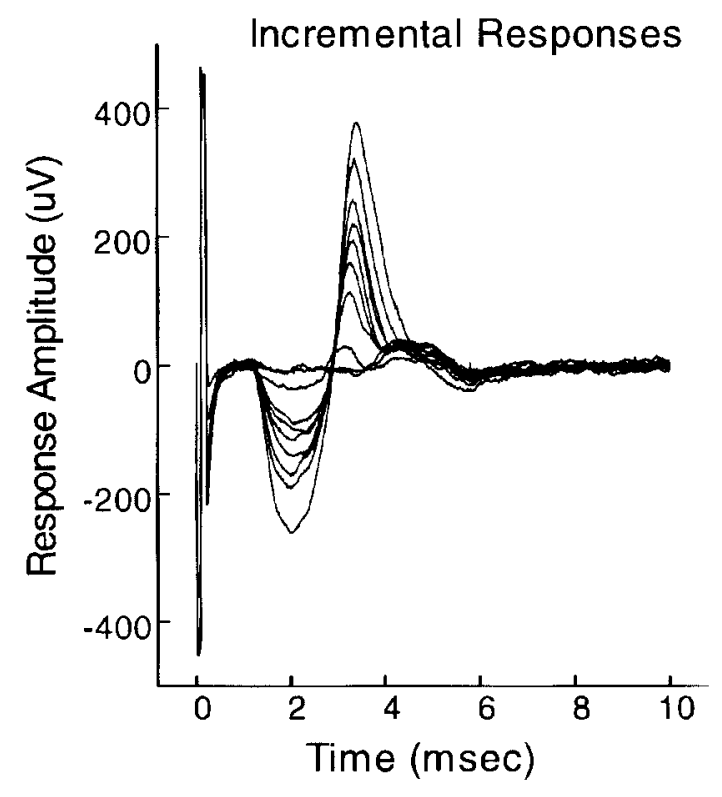

C.

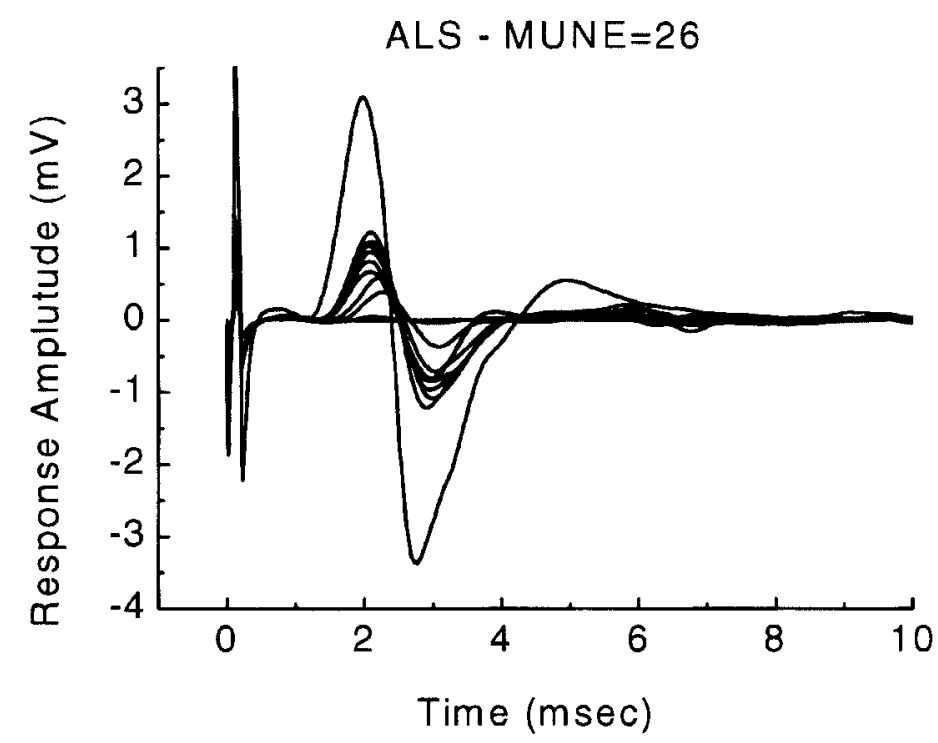

FIG. 1. Examples of incremental MUNE obtained from a wild-type mouse and a symptomatic animal with the FALS transgene. A: $A$ normal maximum compound motor action potential (CMAP). B: 10 incremental responses from the same animal as in A. C: Maximum CMAP and 10 incremental responses displayed at the same amplification from a symptomatic animal. The CMAP is between 2 and 3 times greater than the 10th incremental response, implying a MUNE of between 20 and 30 . In contrast, the 10th incremental response in $\mathrm{B}$ is less than $5 \%$ of the CMAP shown in A. 
Thus, the variability of the response to such stimulus depends on the variable firing of a relatively few units. The statistical technique estimates the size of these units by the variability of the response; this procedure is repeated at four different intensity levels to sample motor unit size as a variety of regions of the stimulus-response curve. These separate estimates are then combined to generate an average single motor unit size.

In theory, lower motor neuron dropout in ALS is a process ideally suited to evaluation by MUNE. Both the actual loss of motor units and the functional adaptation of increasing motor unit size can be estimated, the process is noninvasive, well tolerated, and fairly rapid to perform. Early studies showed that MUNE was indeed reduced in patients with ALS. Hansen and Ballantyne ${ }^{88}$ compared MUNE in intrinsic foot muscles of normal subjects and 32 patients with ALS. Overall, MUNE of the patients was reduced by $62 \%$, whereas individual motor unit potential amplitude increased by $145 \%$. Carleton and Brown ${ }^{89}$ obtained similar findings in the upper extremities. Because of compensatory increase in motor unit size, compound motor action potential amplitude was within normal limits until MUNE dropped below $10 \%$ of normal numbers. This provided a clear explanation for the lack of sensitivity of routine motor nerve conduction studies in identifying patients with ALS.

Progressive decline of MUNE in ALS was first shown by Dantes and McComas ${ }^{90}$; their data suggested that motor unit loss occurred more rapidly early in the disease, with the slope of motor unit decline leveling off after the first year. Similarly, Arasaki and Tamaki ${ }^{11}$ noted that MUNE dropped by $70 \%$ in the first year after diagnosis. Coupled with data showing that muscle strength declines quite linearly in ALS during most of the course of the disease, ${ }^{37,92,93}$ these studies suggested that the early rapid decline in motor unit numbers is compensated for by increases in individual motor unit force generating capacity.

Motor unit dropout is a hallmark of progression in ALS, and virtually all force and electrophysiological measures show declines with time after diagnosis. Hence, the fact that MUNE behaves similarly does not confer upon it any unique utility. However, MUNE has shown promise in stratifying patients according to rate of progression. In a recent study, the rate of change of MUNE was shown to be a strong predictor of survival in ALS patients. ${ }^{94}$ Even a single MUNE study can provide predictive power; using a single MUNE evaluation and extrapolation to normal values assumed to be present just before disease onset, patient survival was effectively predicted. ${ }^{77,95,96}$

The most powerful application of MUNE would be as an outcome measure in clinical trials, if variability of measurement were sufficiently low, and changes in MUNE over time were a more sensitive indicator of disease progression than other surrogate measures. When MUNE, compound motor action potential amplitude, hand grip, strength testing, and vital capacity were all measured at regular intervals during the course of a clinical trial in ALS, ${ }^{78}$ MUNE showed a higher percent change than any other measure, and had a higher likelihood of detecting a criterion change in response than any of the others. Similarly, a study comparing MUNE to grip strength and compound motor action potential amplitude showed a significant decrease in MUNE within 3 months but no significant change in other measures. ${ }^{79}$

In a recently completed multicenter trial evaluating the efficacy of creatine in ALS, MUNE was employed as a secondary outcome measure. Formal training of evaluators was provided, and rigorous criteria for test-retest reliability were applied. Under these circumstances, evaluation of test-retest variability was less than $20 \%$, and MUNE dropped approximately $30 \%$ over a 6-month test interval. Comparison of the decline in MUNE with the changes measured in the other measures of disease progression employed in this study suggested that MUNE could be effectively employed as an outcome measure in future ALS trials. ${ }^{97}$

Transcranial magnetic stimulation. Physiological assessment of upper motor neuron function can be accomplished using both transcranial electrical cortical stimulation and, more recently, transcranial magnetic stimulation (TMS). ${ }^{98}$ TMS employs a brief and powerful magnetic pulse to induce an electric current within the cortex. With cortical magnetic stimulation of appropriate brain areas, a response can be recorded in both upper extremity and lower extremity muscles. By subtracting peripheral conduction time from the total response latency after cortical stimulation, central motor conduction time (CMCT) may be calculated. This measures latency from activation of Betz cells or their input pathways through anterior horn cell activation. Peripheral conduction time can be measured directly by magnetic stimulation of cervical roots or by using $\mathrm{F}$ waves, which assess conduction time from the recording site to the level of the anterior horn cell axon hillock. Abnormally prolonged CMCT has been reported in $51 \%$ to $93 \%$ of patients with ALS. This prolongation may be attributable to the loss of large myelinated motor axons in the corticospinal tracts subsequent to degeneration of cortical motor neurons. However, as can be concluded from the range of abnormal responses discussed above, CMCT prolongation is not a sensitive measure of upper motor neuron disease presence. Even in patients with definite ALS and upper motor neuron abnormalities in the limb studied, less than $50 \%$ of patients may show CMCT abnormalities. ${ }^{99} \mathrm{CMCT}$ prolongation has been found in a variety of CNS diseases, and cannot be considered to be a specific sign of motor systems diseases. ${ }^{99}$ Despite its limited sensitivity and specificity, however, it is possible 
that, for those patients in which CMCT is abnormal, changes over time could correlate with clinical progression. Longitudinal studies to address this issue are currently unavailable.

TMS can provide other measures that have potential as markers of disease progression in ALS. Response amplitude from cortical stimulation can be compared with the response of the same muscle with distal nerve stimulation; the ratio provides some insight into the extent to which the corticomotor neuron is impaired. ${ }^{100}$ However, response variability is even greater than that seen in CMCT studies, and there is no longitudinal information relating this measure to disease progression. Other measures of potential interest include resting threshold of the motor cortex, which may be either normal or reduced even when there is clear loss of corticomotor neurons. ${ }^{101,102}$ Cortical excitability and inhibition can be studied by using peristimulus time histograms (PSTH), whereby a weak transcranial stimulus is superimposed on a steady level of motor activation, and time-related changes in activation are recorded. ${ }^{93,102-104}$ Patients with ALS usually show abnormal PSTH, whereas patients with isolated lower motor neuron disease do not. ${ }^{104}$ By using paired magnetic stimuli, a cortical silent period after stimulation, which also represents corticospinal inhibition, can be explored; most, though not all ALS patients appear to show reduced inhibition using this metric. ${ }^{102}$ Paired cortical stimuli can also be used to assess both early and late intracortical inhibition. ${ }^{103}$ All of the above measures are often abnormal in ALS patients; however, the variability overlaps values seen in normal controls, and changes with disease duration are variable as well. ${ }^{105}$ Thus, although physiological measurement of upper motor neuron processes may reveal valuable insights regarding the pathophysiology of ALS in the future, they are not currently appropriate for use as markers of disease existence or progression.

MRS. The search for a marker of upper motor neuron damage has also included investigations of proton MRS. With this technique, the distributions of multiple small molecules, including $N$-acetyl (NA), $N$-acetylaspartate (NAA), $N$-acetylglutamate (NAG), creatine (Cr), choline (Cho), and others can be determined throughout the brain with a variable degree of spatial resolution. At present, no consensus has been reached regarding the optimal techniques for performing MRS studies, therefore results from different groups are difficult to compare. However, it seems clear that NA concentrations are reduced in the motor region of ALS patients, either expressed directly as concentration or in ratios with other metabolites in the area, such as Cho or Cr. ${ }^{103,106-113}$ Differences in specific metabolite ratios may distinguish disease subtypes. For example, in one study the NAA/Cho ratio selected for patients with definite ALS by El Escorial criteria, as compared with patients who had less obvious motor cor- tex involvement. ${ }^{110}$ In addition, decreases in the NAA/Cr ratio were closely correlated with rate of finger-tapping in ALS patients, which was chosen as a measure of upper motor neuron involvement. ${ }^{107}$ Thus, MRS may have utility as a biomarker for upper motor neuron integrity and function.

A few studies have evaluated longitudinal changes in MR spectra. ${ }^{14}$ In a single patient, NA/Cr dropped $23 \%$ over 8 months. However, in the context of a clinical trial of intrathecal brain-derived neurotrophic factor, NAA/Cr in both patients treated with a placebo or an active drug did not change after 1 month of treatment. ${ }^{114}$ Similarly, treatment with gabapentin for approximately 1 month was not associated with any change in the above ratio in ALS patients or normal controls, ${ }^{115}$ although the ratio was significantly reduced in the patients as compared with the control group. However, in another short-term comparison of ALS patients and control subjects treated with creatine, the NAA/Cr ratio was diminished in the control group but unchanged in the ALS group. ${ }^{116}$ This finding was taken to support the hypothesis that creatine supplementation attenuated the diminished NAA levels seen in ALS motor cortex, and suggests the possible utility of this ratio as a biomarker for therapeutic efficacy. However, because creatine has so far failed to demonstrate any efficacy in patients with ALS, the significance of this finding is unclear. ${ }^{117}$ In a similar study, short-term exposure to riluzole was also found to increase the NAA/Cr ratio in ALS patients. Because riluzole has no short-term clinical benefit that can be measured using the same time scale, it is unclear whether this finding suggests that MRS has potential as a sensitive marker of potential treatment efficacy, or if it is susceptible to multiple epiphenomena.

\section{BIOMARKERS}

No single biochemical abnormality is specific to the diagnosis of ALS. Some have been evaluated as specific and sensitive markers of the disease, although none has proven to be robust. These have included CSF studies, such as measures of protein content, amino acids, and glutamate. ${ }^{118,119}$ Some markers of oxidative injury are elevated in the CSF of patients with ALS, including indices of DNA oxidative injury, ${ }^{120}$ protein oxidation, ${ }^{121}$ and lipid peroxides. ${ }^{122}$ Other reported biochemical changes include increased serum levels of lipid peroxides in sporadic ALS, ${ }^{123}$ and increased serum levels of matrix metalloproteinase- $9^{124}$ and transforming growth factor- $1 .{ }^{125}$ These biochemical changes are not specific to ALS and have low sensitivity.

Proteomics and metabolomics are the comprehensive study of proteins and small molecules present in cells and tissue, respectively. These technologies are just now being applied to ALS. Preliminary data from proteomic 
studies in $\mathrm{CSF}^{126}$ and metabolomic studies in plasma ${ }^{127}$ from subjects with ALS suggest that these technologies will likely yield new insights into disease mechanisms, and potential biomarkers for diagnosis and for following response to therapies in clinical trials.

In recent years there has been an increasing interest in the concept that seemingly benign genetic variants may confer risk for a given disease or a phenotype within a disease. Variations in several genes relevant to motor neuron biology have been considered as possible modifying or risk factors for ALS. One example is the survival motor neuron gene (SMN); deficiency of the telomeric but not the centromeric copy of SMN causes recessively inherited spinal muscular atrophy. The centromeric copy of SMN modifies the phenotype of SMA. Detailed analyses of centromeric and telomeric SMN genes in patients with ALS and controls document that some variants in SMN appear to modify clinical parameters in sporadic ALS cases. ${ }^{128-131}$ Polymorphisms or variants in other genes have also been considered as risk factors for ALS, including apolipoprotein $\mathrm{E},{ }^{132-135}$ ciliary neurotrophic factor, ${ }^{136-140}$ the astrocytic glutamate transporter EAAT2/GLT1, ${ }^{141,142}$ and the ALS2 gene. Most recently, the possibility of a genetic predisposition in ALS was underscored by a recent report of a high rate of constitutional chromosomal aberrations $(5.9 \%$ vs $0.5-$ $0.1 \%$ in the general population. ${ }^{143}$

In summary, disease progression of ALS can be followed using a wide variety of measures. Many have useful attributes, such as intuitive relationship to clinically meaningful outcome and good test-retest reliability. However, no measure directly correlates with underlying pathophysiological changes, and it is unclear to what extent measures are affected by factors other than disease-related progression. Also unknown is the sensitivity of any measure in detecting a therapeutic benefit from a drug or other treatment modality. To address this issue, a positive treatment trial with multiple outcome measures is required. With such a study, relative sensitivity of outcome measures could be determined, and their relationship to survival could be delineated as well. Until such a study is available, debate will continue as to what measures are most relevant to disease progression or to assessing the outcome of potential therapies.

\section{REFERENCES}

1. Mulder D. Clinical limits of amyotrophic lateral sclerosis. In: Human motor neuron diseases (Rowland L, ed), pp 15-22. New York: Raven, 1982.

2. Kurtzke J, Kurland L. The epidemiology of neurologic disease. In: Clinical neurology (Joynt R, ed), pp 1-43. Philadelphia: J.B. Lippincot, 1989.

3. Bensimon G, Lacomblez L, Meininger V. A controlled trial of Riluzole in amyotrophic lateral sclerosis. N Engl J Med 330:585591, 1994.

4. Lacomblez L, Bensimon G, Leigh P, Guillett P, Meininger V. Dose-ranging study of riluzole in amyotrophic lateral sclerosis. Lancet 347:1425-1431, 1996.
5. Rosen DR, Siddique T, Patterson D, Figlewicz DA, Sapp P, Hentati A et al. Mutations in $\mathrm{Cu} / \mathrm{Zn}$ superoxide dismutase are associated with familial amyotrophic lateral sclerosis. Nature 362:59-62, 1993.

6. Mitsumoto H. Diagnosis and progression of ALS. Neurology 48:S2-S8, 1997.

7. Rowland L. Diagnosis of amyotrophic lateral sclerosis. J Neurol Sci 160(Suppl):6-24, 1998.

8. Brooks BR. El Escorial World Federation of Neurology criteria for the diagnosis of amyotrophic lateral sclerosis. J Neurol Sci 124:96-107, 1994.

9. Kent-Braun J, Walker C, Weiner M. Upper and lower motor neuron function and muscle weakness in amyotrophic lateral sclerosis. Neurology 46:A472, 1996.

10. Chan S, Sungu D, Douglas-Akinwande A, Lange D, Rowland L. Motor neuron diseases: comparison of single-voxel proton MR spectroscopy of the motor cortex with MR imaging of the brain. Radiology 212:763-769, 1999.

11. Ellis C, Simmons A, Jones D, Bland J, Dawson J, Horsfield M et al. Diffusion tensor MRI assesses corticospinal tract damage in ALS. Neurology 53:1051-1058, 1999.

12. Pioro EP, Antel JP, Cashman NR, Arnold DL. Detection of cortical neuron loss in motor neuron disease by proton magnetic resonance spectroscopic imaging in vivo. Neurology 44:19331938, 1994.

13. Suhy J, Schuff N, Maudslley A, Weiner M, Miller R. Detection of ALS by proton magnetic resonance imaging. Neurology 54: A254-A255, 2000.

14. Suhy J, Miller R, Rule R, Schuff N, Licht J, Dronsky V et al. Early detection and longitudinal changes in amyotrophic lateral sclerosis by (1) H MRSI. Neurology 58:773-779, 2002.

15. Sach M, Winkler G, Glauche V, Liepert J, Heimbach B, Koch MA, Buchel C, Weiller C. Diffusion tensor MRI of early upper motor neuron involvement in amyotrophic lateral sclerosis. Brain 127:340-350, 2004.

16. Gurney ME, Pu H, Chiu AY, Dal Canto MC, Polchow CY, Alexander DD et al. Motor neuron degeneration in mice that express a human $\mathrm{Cu} / \mathrm{Zn}$ superoxide dismutase mutation. Science 264:1772-1775, 1994.

17. Hayward L, Rodriguez J, Kim J, Tiwari A, Goto J, Cabelli D et al. Decreased metallation and activity in subsets of mutant superoxide dismutases associated with familial ALS. $J$ Biol Chem 15923-31, 2002.

18. Pasinelli P, Borchelt D, Houseweart M, Cleveland D, Brown R. Caspase-1 is activated in neural cells and tissue with amyotrophic lateral sclerosis-associated mutations in copper-zinc superoxide dismutase. Proc Natl Acad Sci USA 95:15763-15768, 1998.

19. Pasinelli P, Houseweart M, Brown R, Cleveland D. Caspase-1 and -3 are sequentially activated in motor neuron death in $\mathrm{Cu} / \mathrm{Zn}$ superoxide dismutase mediated familial amyotrophic lateral sclerosis. Proc Natl Acad Sci USA 97:13901-13906, 2000.

20. Cleveland D, Rothstein J. From Charcot to Lou Gehrig: deciphering selective motor neuron death in ALS. Nat Rev Neurosci 2:806-819, 2001.

21. Yang Y, Hentati A, Deng H, Dabbagh O, Sasaki T, Hirano M et al. The gene encoding alsin, a protein with three guanine-nucleotide exchange factor domains, is mutated in a form of recessive amyotrophic lateral sclerosis. Nat Genet 29:160-165, 2001.

22. Hadano S, Hand C, Osuga H, Yanagisawa Y, Otomo A, Devon R et al. A gene encoding a putative GTPase regulator is mutated in familial amyotrophic lateral sclerosis 2. Nat Genet 29:166-173, 2001.

23. Puls I, Jonnakuty C, LaMonte B, Holzbaur E, Tokito M, Mann E et al. Mutant dynactin in motor neuron disease. Nat Genet 33: 455-456, 2003.

24. Zhao C, Takita J, Tanaka Y, Setou M, Nakagawa T, Takeda S et al. Charcot-Marie-Tooth disease type $2 \mathrm{~A}$ caused by mutation in a microtubule motor KIF1B $\beta$. Cell 105:587-597, 2001.

25. Siddique T, Hong S, Brooks BR, Hung W, Siddique N, Rimmler $\mathrm{J}$ et al. X-linked dominant locus for late-onset familial amyotrophic lateral sclerosis. Am J Hum Genet A308, 1998.

26. Hand C, Khoris J, Salachas T. A novel locus for familial amyo- 
trophic lateral sclerosis on chromosome 18q. Am J Hum Genet 70:251-256, 2002.

27. Chance P, Rabin B, Ryan S, Ding Y, Scavina M, Crain B et al. Linkage of the gene for an autosomal dominant form of juvenile amyotrophic lateral sclerosis to chromosome 9q34. Am J Hum Genet 62:633-640, 1998.

28. Andres PL, Finison L, Conlon T, Thibodeau LM, Munsat TL. Use of composite scores (megascores) to measure deficit in amyotrophic lateral sclerosis. Neurology 38:405-408, 1988.

29. Andres P, Hedlund W, Finison L, Conlon T, Felmus M, Munsat $\mathrm{T}$. Quantitative motor assessment in amyotrophic lateral sclerosis. Neurology 36:937-941, 1986.

30. Andres PL, Thibodeau LM, Finison LJ, Munsat TL. Quantitative assessment of neuromuscular deficit in ALS. Neurol Clin 5:125141, 1987.

31. Munsat T, Andres P, Finison L, Conlon T, Thibodeau L. The natural history of motorneuron loss in amyotrophic lateral sclerosis. Neurology 38:409-413, 1988.

32. Miller R, Petajan J, Bryan W, Armon C, Barohn R, Goodpasture $\mathrm{J}$ et al. A placebo-controlled trial of recombinant human ciliary neurotrophic (rhCNTF) factor in amyotrophic lateral sclerosis. Ann Neurol 39:256-260, 1996.

33. Miller R, Moore DH, Young L, Western ALS Study Group. Placebo-controlled trial of gabapentin in patients with amyotrophic lateral sclerosis. Neurology 47:1383-1388, 1996.

34. Cudkowicz M, Shefner J, Schoenfeld D, Brown RJ, Johnson H, Qureshi $\mathrm{M}$ et al. A randomized, placebo-controlled trial of topiramate in amyotrophic lateral sclerosis. Neurology 61:456-464, 2003.

35. Miller RG, Moore DH, Gelinas DF, Dronsky B, Mendoza M, Barohn $\mathrm{R}$ et al. Phase III randomized trial of gabapentin in patients with amyotrophic lateral sclerosis. Neurology 56:843848, 2001.

36. Hoagland R, Mendoza M, Armon C, Barohn RJ, Bryan WW, Goodpasture JC et al. Reliability of maximal voluntary isometric contraction testing in a multicenter study of patients with keamyotrophic lateral sclerosis. Syntex/Synergen Neuroscience Joint Venture rhCNTF ALS Study Group. Muscle Nerve 20:691695, 1997.

37. Andres PL, Hedlund W, Finison L, Conlon T, Felmus M, Munsat TL. Quantitative motor assessment in amyotrophic lateral sclerosis. Neurology 36:937-941, 1986.

38. ALS CNTF Treatment Study Group. A double-blind placebocontrolled clinical trial of subcutaneous recombinant human ciliary neurotrophic factor (rhCNTF) in amyotrophic lateral sclerosis. Neurology 46:1244-1249, 1996.

39. Smith R, Melmed S, Sherman B, Fane J, Munsat T, Festoff B. Recombinant growth hormone treatment of amyotrophic lateral sclerosis. Muscle Nerve 16:624-633, 1993.

40. Stambler N, Charatran M, Cedarbaum J et al. Prognostic indicators of survival in ALS. Neurology 50:66-72, 1998.

41. Pestronk A, Lopate G, Kornberg A, Elliott J, Blume G, Yee W et al. Distal lower motor neuron syndrome with high-titer serum IgM anti-GM1 antibodies: improvement following immunotherapy with monthly plasma exchange and intravenous cyclophosphamide. Neurology 44:2027-2031, 1994.

42. Schneider-Gold C, Beck M, Wessig C, George A, Kele H, Reiners $\mathrm{K}$ et al. Creatine monohydrate in DM2/PROMM: a doubleblind placebo-controlled clinical study. Proximal myotonic myopathy. Neurology 60:500-502, 2003.

43. Drachman D, Chaudhry V, Cornblath D, Kuncl R, Pestronk A, Clawson L et al. Trial of immunosuppression in amyotrophic lateral sclerosis using total lymphoid irradiation. Ann Neurol 35:142-150, 1994.

44. Beck M, Giess R, Wurffel W et al. Comparison of maximal voluntary isometric contraction and Drachman's hand-held dynamometry in evaluating patients with amyotrophic lateral sclerosis. Muscle Nerve 22:1265-1270, 1999.

45. Great Lakes ALS Study Group. A comparison of muscle strength testing techniques in amyotrophic lateral sclerosis, Neurology 61:1503-1506, 2003.

46. Ziter F, Allsop K, Tyler F. Assessment of muscle strength in Duchenne muscular dystrophy. Neurology 27:981-984, 1977.
47. Florence J, Pandya S, King W, Robison J, Signore L, Wentzell M et al. Clinical trials in Duchenne dystrophy. Standardization and reliability of evaluation procedures. Phys Ther 64:41-45, 1984.

48. Brooks B, Sufit R, DePaul R, Tan Y, Sanjak M, Robbins J. Design of clinical therapeutic trials in amyotrophic lateral. In: Amyotrophic lateral sclerosis and other motor neuron disease (Rowland L, ed). New York: Raven, 1991.

49. Lyall RN, Polkey M, Leigh P, Moxham J. Respiratory muscle strength and ventilatory failure in amyotrophic lateral sclerosis. Brain 124:2000-2013, 2001.

50. Varrato J, Siderowf A, Damiano P, Gregory S, Feinberg D, McCluskey L. Postural change of forced vital capacity predicts some respiratory symptoms in ALS. Neurology 57:357-359, 2001.

51. Magnus T, Beck M, Giess R, Puls I, Naumann M, Toyka KV. Disease progression in amyotrophic lateral sclerosis: predictors of survival. Muscle Nerve 25:709-714, 2002.

52. Black L, Hyatt R. Maximal respiratory pressures: normal values and relationship to age and sex. Am Rev Respir Dis 99:696-702, 1969.

53. Appel V, Stewart S, Smith G, Appel S. A rating scale for amyotrophic lateral sclerosis: description and preliminary experience. Ann Neurol 22:328-333, 1987.

54. Haverkamp LJ, Appel V, Appel SH. Natural history of amyotrophic lateral sclerosis in a database population. Validation of a scoring system and a model for survival prediction. Brain 118: 707-719, 1995.

55. The ALS CNTF Treatment Study (ACTS) Phase I-II Study Group. The amyotrophic lateral sclerosis functional rating scale. Arch Neurol 53:141-147, 1996.

56. Cedarbaum J. The amyotrophic lateral sclerosis functional rating scale (ALSFRS). Arch Neurol 53:141-7, 1996.

57. Cedarbaum JM, Stambler N, Malta E, Fuller C, Hilt D, Thurmond $\mathrm{B}$ et al. The ALSFRS-R: a revised ALS functional rating scale that incorporates assessments of respiratory function. BDNF ALS Study Group (Phase III). J Neurol Sci 169:13-21, 1999.

58. Clarke S, Hickey A, O’Boyle C, Hardiman O. Assessing individual quality of life in amyotrophic lateral sclerosis. 149-158, 2001.

59. Cruveilhier J. Sur la paralysie musculaire progressive atrophique. Arch Gen Med 91:561-603, 1853.

60. Charcot JM, Joffroy A. Deux cas d'atrophie musculaire progressive ave lesions de la substance grise et des faisceaux anterolateraux de la moelle epineire. Arch Physiol 2:354-367, 1869.

61. Piao YS, Wakabayashi K, Kakita A, Yamada M, Hayashi S, Morita $\mathrm{T}$ et al. Neuropathology with clinical correlations of sporadic amyotrophic lateral sclerosis: 102 autopsy cases examined between 1962 and 2000. Brain Pathol 13:10-22, 2003.

62. Sasaki S, Iwata M. Ultrastructural study of Betz cells in the primary motor cortex of the human brain. J Anat 199:699-708, 2001.

63. Tsuchiya K, Ikeda K, Mimura M, Takahashi M, Miyazaki H, Anno $\mathrm{M}$ et al. Constant involvement of the Betz cells and pyramidal tract in amyotrophic lateral sclerosis with dementia: a clinicopathological study of eight autopsy cases. Acta Neuropathol (Berl) 104:249-259, 2002.

64. van Welsem ME, Hogenhuis JA, Meininger V, Metsaars WP, Hauw JJ, Seilhean D. The relationship between Bunina bodies, skein-like inclusions and neuronal loss in amyotrophic lateral sclerosis. Acta Neuropathol (Berl) 103:583-589, 2002.

65. Yaguchi M, Hashizume Y, Yoshida M, Gonatas NK, Okamoto K. Reduction of the size of the Golgi apparatus of spinal anterior horn cells in patients with X-linked spinal and bulbar muscular atrophy. Amyotroph Lateral Scler Other Motor Neuron Disord 4:17-21, 2003.

66. Fujita Y, Okamoto K, Sakurai A, Kusaka H, Aizawa H, Mihara B et al. The Golgi apparatus is fragmented in spinal cord motor neurons of amyotrophic lateral sclerosis with basophilic inclusions. Acta Neuropathol (Berl) 103:243-247, 2002.

67. Dubowitz V, Brooke MH. Muscle biopsy: a practical approach. London: Bailliere Tindall, 1985.

68. Tsukagoshi H, Yanagisawa N, Oguchi K, Nagashima K, Murakami T. Morphometric quantification of the cervical limb motor 
cells in controls and in amyotrophic lateral sclerosis. J Neurol Sci 41:287-297, 1979.

69. Shefner JM. Motor unit number estimation in human neurological diseases and animal models. Clin Neurophysiol 112:955-64, 2001.

70. Shefner JM, Gooch CL. Motor unit number estimation in neurologic disease. Adv Neurol 88:33-52, 2002.

71. Bromberg MB, Forshew DA, Nau KL, Bromberg J, Simmons Z, Fries TJ. Motor unit number estimation, isometric strength, and electromyographic measures in amyotrophic lateral sclerosis. Muscle Nerve 16:1213-1219, 1993.

72. Shefner JM, Gooch CL. Motor unit number estimation. Phys Med Rehabil Clin N Am 14:243-260, 2003.

73. Bromberg MB, Larson WL. Relationships between motor-unit number estimates and isometric strength in distal muscles in ALS/MND. J Neurol Sci 139(Suppl):38-42, 1996.

74. Bromberg MB, Abrams JL. Sources of error in the spike-triggered averaging method of motor unit number estimation (MUNE). Muscle Nerve 18:1139-1146, 1995.

75. Doherty TJ, Stashuk DW, Brown WF. Determinants of mean motor unit size: impact on estimates of motor unit number. Muscle Nerve 16:1326-1331, 1993.

76. Lomen-Hoerth C, Olney RK. Comparison of multiple point and statistical motor unit number estimation. Muscle Nerve 23:15251533, 2000.

77. Armon C, Brandstater ME. Motor unit number estimate-based rates of progression of ALS predict patient survival. Muscle Nerve 22:1571-1575, 1999.

78. Felice KJ. A longitudinal study comparing thenar motor unit number estimates to other quantitative tests in patients with amyotrophic lateral sclerosis. Muscle Nerve 20:179-185, 1997.

79. Yuen EC, Olney RK. Longitudinal study of fiber density and motor unit number estimate in patients with amyotrophic lateral sclerosis. Neurology 49:573-578, 1997.

80. Daube JR. Estimating the number of motor units in a muscle. J Clin Neurophysiol 12:585-594, 1995.

81. McComas A, Fawcett P, Campbell M, Sica R. Electrophysiological estimation of the number of motor units within a human muscle. J Neurol Neurosurg Psychiatry 34:121-131, 1971.

82. McComas AJ, Galea V, de Bruin H. Motor unit populations in healthy and diseased muscles. Phys Ther 73:868-877, 1993.

83. McComas AJ, Quartly C, Griggs RC. Early and late losses of motor units after poliomyelitis. Brain 120:1415-1421, 1997.

84. Brown WF. A method for estimating the number of motor units in thenar muscles and the changes in motor unit count with ageing. J Neurol Neurosurg Psychiatry 35:845-852, 1972.

85. Brown WF. Thenar motor unit count estimates in the carpal tunnel syndrome. J Neurol Neurosurg Psychiatry 36:194-198, 1973.

86. Olney RK, Yuen EC, Engstrom JW. Statistical motor unit number estimation: reproducibility and sources of error in patients with amyotrophic lateral sclerosis. Muscle Nerve 23:193-197, 2000.

87. Shefner JM, Jillapalli D, Bradshaw DY. Reducing intersubject variability in motor unit number estimation. Muscle Nerve 22: 1457-1460, 1999.

88. Hansen S, Ballantyne JP. A quantitative electrophysiological study of motor neurone disease. J Neurol Neurosurg Psychiatry 41:773-783, 1978.

89. Carleton SA, Brown WF. Changes in motor unit populations in motor neurone disease. J Neurol Neurosurg Psychiatry 42:42-51, 1979.

90. Dantes M, McComas A. The extent and time course of motoneuron involvement in amyotrophic lateral sclerosis. Muscle Nerve 7:416-421, 1991.

91. Arasaki K, Tamaki M. A loss of functional spinal alpha motor neurons in amyotrophic lateral sclerosis. Neurology 51:603-605, 1998.

92. Andres PL, Thibodeau LM, Finison LJ, Munsat TL. Quantitative assessment of neuromuscular deficit in ALS. Neurol Clin 5:125$141,1987$.

93. Andres PL, Finison LJ, Conlon T, Thibodeau LM, Munsat TL. Use of composite scores (megascores) to measure deficit in amyotrophic lateral sclerosis. Neurology 38:405-408, 1988.
94. Olney R, Yuen E, Engstrom J. The rate of change in motor unit number estimates predicts survival in patients with amyotrophic lateral sclerosis. Neurology 52(Suppl 2):A3, 1999.

95. Armon C, Moses D. Linear estimates of rates of disease progression as predictors of survival in patients with ALS entering clinical trials. J Neurol Sci 160:(Suppl 1):S37-S41, 1998.

96. Armon C, Graves MC, Moses D, Forte DK, Sepulveda L, Darby $\mathrm{SM}$ et al. Linear estimates of disease progression predict survival in patients with amyotrophic lateral sclerosis. Muscle Nerve 23: $874-882,2000$.

97. Shefner JM. Motor unit number estimation in a multicenter clinical trial. Paper presented at the 14th international symposium on ALS/MND, Milan, Italy, November, 2003.

98. Eisen A, Swash M. Clinical neurophysiology of ALS. Clin Neurophysiol 112:2190-2201, 2001.

99. Urban PP, Wicht S, Hopf HC. Sensitivity of transcranial magnetic stimulation of cortico-bulbar vs. cortico-spinal tract involvement in amyotrophic lateral sclerosis (ALS). J Neurol 248:850-855, 2001.

100. Hess CW, Mills KR, Murray NMF, Schriefer TN. Magnetic brain stimulation: central motor conduction studies in multiple sclerosis. Ann Neurol 22:744-752, 1987.

101. Mills KR, Nithi KA. Corticomotor threshold is reduced in early sporadic amyotrophic lateral sclerosis. Muscle Nerve 20:11371141, 1997.

102. Eisen A, Pant B, Stewart H. Cortical excitability in amyotrophic lateral sclerosis: a clue to pathogenesis. Can J Neurol Sci 20:1116, 1993.

103. Ziemann U, Winter M, Reimers CD, Reimers K, Tergau F, Paulus W. Impaired motor cortex inhibition in patients with amyotrophic lateral sclerosis. Evidence from paired transcranial magnetic stimulation. Neurology 49:1292-1298, 1997.

104. Weber M, Eisen A. Assessment of upper and lower motor neurons in Kennedy's disease: implications for corticomotoneuronal PSTH studies. Muscle Nerve 22:299-306, 1999.

105. Zanette G, Tamburin S, Manganotti P, Refatti N, Forgione A, Rizzuto N. Changes in motor cortex inhibition over time in patients with amyotrophic lateral sclerosis. J Neurol 249:17231728, 2002.

106. Sarchielli P, Pelliccioli GP, Tarducci R, Chiarini P, Presciutti O, Gobbi $\mathrm{G}$ et al. Magnetic resonance imaging and $1 \mathrm{H}$-magnetic resonance spectroscopy in amyotrophic lateral sclerosis. Neuroradiology 43:189-197, 2001

107. Rooney WD, Miller RG, Gelinas D, Schuff N, Maudsley AA, Weiner MW. Decreased N-acetylaspartate in motor cortex and corticospinal tract in ALS. Neurology 50:1800-1805, 1998.

108. Pioro EP. Proton magnetic resonance spectroscopy (1H-MRS) in ALS. Amyotroph Lateral Scler Other Motor Neuron Disord 1:S7-S16, 2000.

109. Pioro EP, Majors AW, Mitsumoto H, Nelson DR, Ng TC. 1HMRS evidence of neurodegeneration and excess glutamate + glutamine in ALS medulla. Neurology 53:71-79, 1999.

110. Pohl C, Block W, Karitzky J, Traber F, Schmidt S, Grothe C et al. Proton magnetic resonance spectroscopy of the motor cortex in 70 patients with amyotrophic lateral sclerosis. Arch Neurol 58:729$735,2001$.

111. Kenn W, Ochs G, Pabst TA, Hahn D. 1H spectroscopy in patients with amyotrophic lateral sclerosis. J Neuroimaging 11:293-297, 2001.

112. Bowen BC, Bradley WG. Amyotrophic lateral sclerosis: the search for a spectroscopic marker of upper motoneuron involvement. Arch Neurol 58:714-716, 2001.

113. Bowen BC, Pattany PM, Bradley WG, Murdoch JB, Rotta F, Younis AA et al. MR imaging and localized proton spectroscopy of the precentral gyrus in amyotrophic lateral sclerosis. AJNR Am J Neuroradiol 21:647-658, 2000.

114. Kalra S, Genge A, Arnold DL. A prospective, randomized, placebo-controlled evaluation of corticoneuronal response to intrathecal BDNF therapy in ALS using magnetic resonance spectroscopy: feasibility and results. Amyotroph Lateral Scler Other Motor Neuron Disord 4:22-26, 2003.

115. Kalra S, Cashman NR, Caramanos Z, Genge A, Arnold DL. Gabapentin therapy for amyotrophic lateral sclerosis: lack of 
improvement in neuronal integrity shown by MR spectroscopy. AJNR Am J Neuroradiol 24:476-480, 2003.

116. Vielhaber S, Kaufmann J, Kanowski M, Sailer M, Feistner H, Tempelmann $\mathrm{C}$ et al. Effect of creatine supplementation on metabolite levels in ALS motor cortices. Exp Neurol 172:377-382, 2001.

117. Groeneveld GJ, Veldink JH, van der Tweel I, Kalmijn S, Beijer $\mathrm{C}$, de Visser $\mathrm{M}$ et al. A randomized sequential trial of creatine in amyotrophic lateral sclerosis. Ann Neurol 53:437-445, 2003.

118. Rothstein J, Tsai G, Kuncl R et al. Abnormal excitatory amino acid metabolism in amyotrophic lateral sclerosis. Ann Neurol 28:18-25, 1990.

119. Camu W, Billiard M, Baldy-Moulinier M. Fasting plasma and CSF amino acid levels in amyotrophic lateral sclerosis: a subtype analysis. Acta Neurol Scand 88:51-55, 1993.

120. Bogdanov M, Brown R, Matson W, Hayden D, O’Donnell H, Beal $\mathrm{F}$ et al. Increased oxidative damage to DNA in ALS patients. Free Radical Biology 29:652-658, 2000.

121. Beal M, Ferrante R, Browne S, Matthews R, Kowall N, Brown R. Increased 3-Nitrotyrosine in both sporadic and familial amyotrophic lateral sclerosis. Ann Neurol 42:644-654, 1997.

122. Smith R, Henry Y, Mattson M, Appel S. Presence of 4-hydroxynonenal in cerebrospinal fluid of patients with sporadic amyotrophic lateral sclerosis. Ann Neurol 44:696-699, 1998.

123. Simpson E, Henkel J, Henry Y, Smith R, Appel S. Elevated levels of 4-HNE in the sera of patients with amyotrophic lateral sclerosis. Neurology 60:A242, 2003.

124. Beuche W, Yushchenko M, Mader M, Maliszewska M, Felgenhauer K, Weber F. Matrix metalloproteinase-9 is elevated in serum of patients with amyotrophic lateral sclerosis. NeuroReport 11:3419-3422, 2000.

125. Houi K, Kobayashi T, Kato S, Mochio S, Inoue K. Increased plasma TGF-beta1 in patients with amyotrophic lateral sclerosis. Acta Neurol Scand 106:299-301, 2002.

126. Ranganathan S, Jordan K, Sathanoonri R, Henry S, Wood P, Urbinelli $\mathrm{L}$ et al. Identification of ALS specific biomarkers by protein profiling of cerebral spinal fluid. Amyotroph Lateral Scler Other Motor Neuron Disord 4:12, 2003.

127. Bogdanov M, Rozen S, Kristall B, Matson W, Vigneau-Callahan $\mathrm{K}$, Flarakos J et al. Metabolic profiling and signatures in ALS. Amyotroph Lateral Scler Other Motor Neuron Disord 3:26, 2002.

128. Jackson M, Morrison K, al-Chalabi A, Bakker M, Leigh P. Analysis of chromosome $5 \mathrm{q} 13$ genes in amyotrophic lateral sclerosis: homozygous NAIP deletion in a sporadic case. Ann Neurol 39: 796-800, 1996.

129. Parboosingh J, Meininger V, McKenna-Yasek D, Brown RJ, Rouleau G. Deletions causing spinal muscular atrophy do not predispose to amyotrophic lateral sclerosis. Arch Neurol 56:710 712, 1999.

130. Moulard B, Salachas F, Chassande B. Association between centromeric deletions of the SMN gene and sporadic adult-onset lower motor neuron disease. Ann Neurol 43:640-644, 1998.

131. Corcia P, Mayeux-Portas V, Khoris J. Abnormal SMN1 gene copy number is a susceptibility factor for amyotrophic lateral sclerosis. Ann Neurol 51:243-246, 2002.

132. Mui S, Rebeck G, McKenna-Yasek D, Hyman B, Brown R. Apolipoprotein E E4 allele is not associated with earlier age at onset in amyotrophic lateral sclerosis. Ann Neurol 38:460-463, 1995.

133. Al-Chalabi A, Enayat Z, Bakker M et al. Association of apolipoprotein E E4 allele with bulbar-onset motor neuron disease. Lancet 347:159-160, 1996.

134. Moulard B, Sefiani A, Laamri A, Malafosse A, Camu W. Apolipoprotein E genotyping in sporadic amyotrophic lateral sclerosis: evidence for a major influence on the clinical presentation and prognosis. J Neurol Sci 139(Suppl):34-137, 1996.

135. Smith R, Haverkamp L, Case S, Appel S, Appel V. Apolipoprotein E E4 in bulbar-onset motor neuron disease. Lancet 348:334 $335,1996$.

136. Takahashi R. Deficiency of human ciliary neurotrophic factor (CNTF) is not causally related to amyotrophic lateral sclerosis (ALS). Rinsho Shinkeigakku 35:1543-1545, 1995.

137. Takahashi R, Yokoji $\mathrm{H}$, Misawa $\mathrm{H}$ et al. A null mutation in the human CNTF gene is not causally related to neurological diseases. Nat Genet 7:79-84, 1994.

138. Orrell R, King A, Lane R, de Belleroche J. Investigation of a null mutation of the CNTF gene in familial amyotrophic lateral sclerosis. J Neurol Sci 132:126-128, 1995.

139. Masu Y, Wolf E, Holtmann B et al. Disruption of the CNTF gene results in motor neuron degeneration. Nature 365:27-32, 1993.

140. Al-Chalabi A, Scheffler M, Smith B, Parton M, Cudkowicz M, Andersen $\mathrm{P}$ et al. CNTF genotype does not influence clinical phenotype in amyotrophic lateral sclerosis. Ann Neurol 54:130134, 2003.

141. Lin C, Bristol L, Jin L, Dykes-Hoberg M, Crawford T, Clawson $\mathrm{L}$ et al. Aberrant RNA processing in a neurodegenerative disease: the cause for absent EAAT2, a glutamate transporter, in amyotrophic lateral sclerosis. Neuron 20:589-602, 1998.

142. Trotti D, Rolfs A, Danbolt N, Brown R, Hediger M. SOD1 mutants linked to amyotrophic lateral sclerosis selectively inactivate a glial glutamate transporter. Nat Neurosci 2:427-433, 1999.

143. Meyer T, Albert B, Roemer K, Martin T, Kalscheuer V, Gottert $\mathrm{E}$ et al. High rate of constitutional chromosomal rearrangements in apparently sporadic ALS. Neurology 60:1348-1350, 2003. 